\title{
The Effectiveness of Digital Teaching Materials on Introduction Statistics
}

\author{
Linghui Yang \\ Department of Food and Beverage Management, \\ Tatung Institute of Commerce and Technology \\ Chiayi City, Taiwan, R.O.C. \\ linghuey@ms2.ttc.edu.tw
}

Derching Yang

Graduate Institute of Mathematics and Science Education, National Chiayi University

Chiayi City, Taiwan, R.O.C.

dcyang@mail.ncyu.edu.tw

\begin{abstract}
This study developed digital multimedia materials to enhance college students' number sense in statistics course. Sample students' attitudes were assessed before and after the formal statistics course. Significant effects were found for four attitude subscales (Affect, Value, Difficulty, and Cognitive Competence), and the scores in attitudes (posttest-pretest) increased when digital multimedia educational materials used as a supplement in teaching statistics.
\end{abstract}

Keyword-attitudes toward statistics; digital teaching materials; statistics course

\section{INTRODUCTION}

In the era of the knowledge-based economy, the capabilities, such as innovation, problem solving, critical thinking and the ability to apply information technology, are all important for future citizens [1]. An ultimate goal of statistics education is to produce statistically literate adults who can appropriately use statistical thinking [2]. In investigating the problems of statistics education, most researches support that the students who leave their introduction statistics courses with negative attitudes are unlikely ever to use what they have learned, that is, they will not intelligently and literately use statistics in their professional and personal lives or in any educational venture [3]. In addition, Chick and Pierce [4] indicated that the growing recognition of the importance of statistics in everyday life and the concerns about statistical literacy have resulted in a great focus on the statistics curriculum at the school and the capacity of teachers to deal with that curriculum. According to Bruce [5], learning occurs in the interaction with the learner and the learning environment; when the appropriate strategies and skills are applied to technology use, making it a favorable tool for teaching, then better teaching effectiveness can be developed. In traditional teaching, teachers are the main transmitters of knowledge, while students are passive receivers; but with increasingly sophisticated network and information technology, the role of teachers has gradually changed and new learning models may be generated. Through the applying of information technology and appropriate instruction media to

\author{
Tingsheng Weng* \\ Department of Business Administration, \\ National Chiayi University \\ Chiayi City, Taiwan, R.O.C. \\ politeweng@yahoo.com.tw \\ *Corresponding author
}

\author{
Pohsuan $\mathrm{Wu}$ \\ Department of Baking Technology and Management, \\ Tatung Institute of Commerce and Technology \\ Chiayi City, Taiwan, R.O.C. \\ galingale@ms2.ttc.edu.tw
}

appear the digital teaching material, the teachers' idea will be transmitted and let the instruction effort reach the optimization result [6].

Furthermore, due to teachers only can adopt limited useful parts of the present published materials for assisting their teaching, such as instructional CD, DVD, or internet platform, and reorganize the content to fit essential needs. Thus, the purposes of this study were to develop digital teaching materials to enhance students' number sense in statistics course, as well as evaluation of learning effectiveness.

\section{LITERATURE REVIEW}

\section{A. Digital Teaching Materials}

In the information educational environment, the idea of integration of multimedia in teaching is to connect different multimedia elements, such as text, image, audio, animation, and video, to create digital teaching materials [7]. Digital teaching materials combine the words, pictures, cartoons, and audio-visual films, transferring information to digitization form. The teachers must reexamine the instruction contents of traditional teaching materials and add to and present them as digital teaching material [8]. If teachers can arrange and produce multimedia teaching aids by themselves, the integration of multimedia in classroom teaching will be more effective and efficient and close to teachers' actual needs [9], becoming the right-hand of instruction activity. One of the reasons for utilizing digital teaching materials is not only to improve learning methods to enhance learning interest for the students, but also it affords for learning anywhere, at any place and at any time. Many researches also indicated that the application of computer technology has great potential to increase students' motivation, help learners to connect various information sources, improve the quality of teachers' teaching and students' learning, and create many positive effects in classroom teaching $[10,11,12,13]$. 


\section{B. Statistics Education}

Statistics is needed and used in various fields in our society such as medicine, politics or marketing. In addition, the media reports everyday results of statistical surveys or makes claims based on statistics. Educating students who are able to evaluate statistical information appropriately is obviously a priority of statistics education [14]. During their introductory statistics course, students need to understand and use statistics, think that statistics is useful both in their professional and personal lives, recognize that statistics can be interesting, be willing to invest the effort needed to learn statistical thinking and skills, and, realize that statistics is not easy but it also is not too difficult to learn [2]. Garfield et al. [15] proposed that desired outcomes of introductory statistics courses include not only statistical learning and understanding, but also students' willingness to persist in their learning and application of skills, and positive attitudes and beliefs about statistics.

Research studies on technology in statistics education have pointed out several effective ways to use technology in the statistics classroom. Thus, this study, the researcher designed the digital teaching materials which are close to teaching needs in order to promote more efficiency and effectiveness of instruction activity in introduction statistics course.

\section{METHOD}

\section{A. Multimedia Materials}

Lee [16] also believed the major factors that affect learning effectiveness are learning satisfaction and teaching innovation, but there are many factors that affect the students' learning satisfaction and learning effectiveness, including student's personal factors, teachers, courses, and learning environment. Before teaching, teachers must prepare teaching materials designed to reflect on the course content and the teaching activities, and to enhance students' learning effectiveness. Below we provide some examples of digital teaching materials developed by Flash CS6 in the statistics classroom.

- Visualization of Statistical Concepts and Processes. For example, students can see how to calculate quartile and InterQuartile Range (IQR), plot dot plot and boxplot in a dynamic representations. It is allowed clicking on arrow symbol to control playback speed (Fig. 1).

- Provision of Real Life Event. This example, students can easy construct the sample space of rolling two dice experiment, there are 36 possible outcomes. When we throw two dice we are often interested not in individual numbers that show up, but in their different combination. It is often a convenience to be able to consider several events and random variables related to the same experiment via digital teaching materials (Fig. 2).

Example. To calculate quartile, InterQuartile Range, and plot boxplot for the given data 13101412710715111079

(1) In ascending order, the first quartile is equal to the data at the 25 th percentile of the data. The third quartile is equal to the data at the 75 th percentile of the data. Formula $\mathrm{IQR}=\mathrm{Q}_{3}-\mathrm{Q}_{1}$
(2) Any set of data can be described by its five numbers summary. These five numbers, in ascending order, consist of the minimum, maximum, Q1, median, and Q3.



FIGURE I. ILLUSTRATION OF CALCULATING QUARTILE AND INTERQUARTILE RANGE (IQR), PLOTING BOXPLOT 


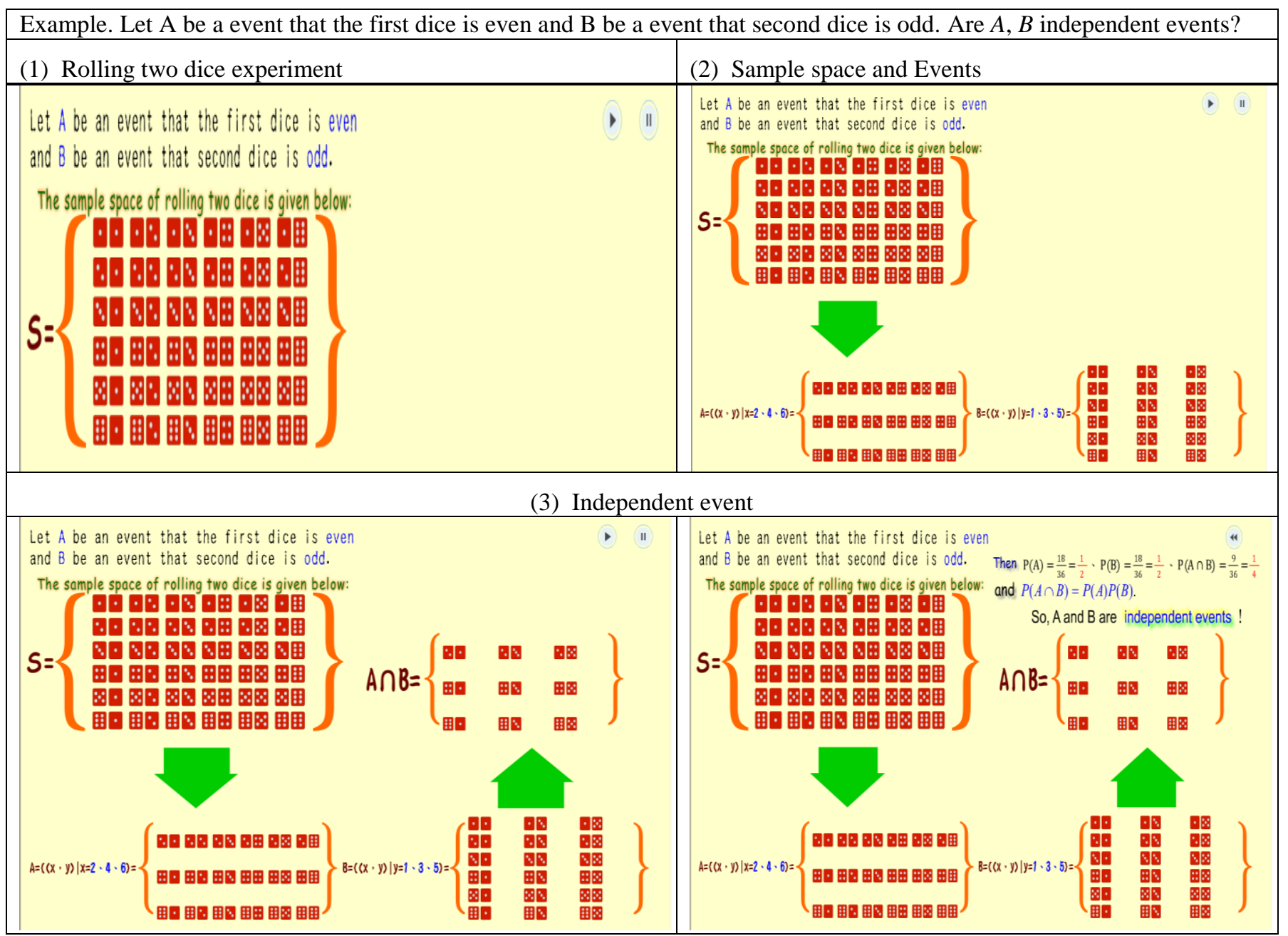

FIGURE II. ILLUSTRATION OF SAMPLE SPACE AND EVENTS OF ROLLING TWO DICE EXPERIMENT

\section{B. Instrument}

The Survey of Attitudes Toward Statistics (SATS-28), developed by [17] with 28 items, were designed to measure attitudes toward statistics based on four components- namely, affect (6 items), cognitive competence (6 items), value (9 items) and difficulty (7 items). A newer version, the SATS-36, contains 36 items that assess six components, the original four plus two more, interest (4 items) and effect (4 items). We developed instrument of attitude toward statistics based upon SATS-36. Students indicated their agreement with each statement using a 5-point Likert-type scale that ranged from 1 (strongly disagree) to 5 (strongly agree). Confirmatory factor analysis was also conducted to establish construct validity. The results of the analysis consisted of six factors and 27 items which alpha coefficient estimates ranged between .75 and 89 . The composite reliability (CR) of individual dimension was between 0.83 and 0.92 , which conformed to the suggested CR of greater than 0.60 , as proposed by [18].

\section{Kano's Model}

Kano's model, proposed by the Japanese professor Noriaki Kano and his colleagues, is a useful tool to understand customer needs and their impact on customer satisfaction [19].
The Kano questionnaire helps to categorize customer requirements into the five Kano categories: Attractive quality element, One-dimensional quality element, Must-be quality element, Indifferent quality element, Reverse quality element. Kano's model provides an effective approach in classifying different education service quality into different categories based on their impact on learners' satisfaction. In this study, we applied Kano's model to categorize education quality about supply of digital teaching materials in statistics course into certain Kano's quality element.

\section{Data AnALYsis}

The study was a pretest-posttest design, the pre-test in order to obtain a baseline of attitudes toward statistics levels before any statistics instruction was given. In order to compare the changes, results were analyzed using paired-sample $t$ tests. These analyses revealed a significant enhancement for four attitude components, Affect, Value, Difficulty, and Cognitive Competence. Students did not have a statistically significant increase in their feeling of interest and effort after their course. We found that it couldn't capture Interest and Effort two components, students' level of individual interest in statistics and amount of work the student expends to learn statistics, which are associated with personality and profession. 
TABLE I. PRE-POSTTEST PAIRED T TEST

\begin{tabular}{|c|c|c|c|c|c|}
\hline \multirow{2}{*}{$\begin{array}{c}\text { Attitudes Toward } \\
\text { Statistics }\end{array}$} & Pre-test & Post-test & \multirow{2}{*}{$\begin{array}{c}\text { Mean } \\
\text { Change }\end{array}$} & \multicolumn{2}{|c|}{$\begin{array}{c}\text { Paired t test } \\
\text { (Post-Pre) }\end{array}$} \\
\cline { 2 - 6 } & $\mathrm{M}(\mathrm{SD})$ & $\mathrm{M}(\mathrm{SD})$ & & $\mathrm{t}$-value & $\mathrm{p}$ \\
\hline Affect & $2.935(.78)$ & $3.491(.66)$ & .556 & $5.922^{* *}$ & .000 \\
\hline Effort & $3.776(.78)$ & $3.809(.63)$ & .033 & 0.299 & .766 \\
\hline Interest & $3.048(.81)$ & $3.118(.85)$ & .070 & 0.682 & .498 \\
\hline Value & $3.006(.61)$ & $3.424(.48)$ & .418 & $6.103^{* *}$ & .000 \\
\hline Difficulty & $3.132(.70)$ & $3.374(.59)$ & .241 & $3.430^{* *}$ & .001 \\
\hline Cognitive Competence & $2.794(.80)$ & $3.338(.77)$ & .544 & $6.008^{* *}$ & .000 \\
\hline
\end{tabular}

"Attractive" quality element: whenever this element is sufficient, people show satisfaction. Even if it is insufficient, it is still acceptable but caused no dissatisfaction. Based on Table II, it revealed that if teachers can arrange and produce multimedia teaching aids, many positive effects can be created in teaching.

TABLE II. THE QUALITY ClASSIFICATION

\begin{tabular}{|c|c|c|c|c|c|c|}
\hline \multicolumn{6}{|c|}{ Kano’'s Model Attribute Classification (\%) } & \multirow{2}{*}{$\begin{array}{c}\text { Attribute } \\
\text { Classification }\end{array}$} \\
\hline A & $\mathrm{O}$ & $\mathrm{M}$ & $\mathrm{I}$ & $\mathrm{R}$ & Q & \\
\hline $43.2 \%$ & $25.0 \%$ & $6.8 \%$ & $22.7 \%$ & $0.0 \%$ & $2.3 \%$ & $\mathrm{~A}$ \\
\hline \multicolumn{3}{|c|}{$\begin{array}{c}\mathrm{A}=\text { Attractive } \\
\mathrm{O}=\text { One-dimensional }\end{array}$} & $\begin{aligned} \mathrm{M} & =\mathrm{Mus} \\
\mathrm{I} & =\mathrm{Indif}\end{aligned}$ & \multicolumn{3}{|c|}{$\begin{array}{l}\mathrm{R}=\text { Reverse } \\
\mathrm{Q}=\text { Questionable }\end{array}$} \\
\hline
\end{tabular}

\section{CONCLUSION}

Technology integration in classroom teaching has been a trend, which is not possible to be reversed [20]. Technology can play a significant role in enhancing students' ability to understand statistical concepts, ideas, and processes. For many learners, this change in awareness and perspective is quite eyeopening and draws them into the course material and activities. Such teaching materials give students much more flexibility of repeating review, and carry out statistical abstract ideas and processes through direct observation. Technology enables integration of statistics, graph data, and analyzing data, visualization of statistical concepts and processes, allows students to focus on interpretation of results and understanding statistical ideas [21]. We assess the impact of digital teaching materials on the role of statistics education, helping students to choose a positive view, explore origins or core of negative attitudes, and to appreciate the usefulness of statistics in their profession. The important part of educating students is preparing them for life outside the classroom, so even if the use of technology does not provide immediate effects in the teaching and learning of statistics concepts and critical thinking, students are learning how to use statistical literacy that they may encounter in their future jobs.

\section{ACKNOWLEDGEMENTS}

The author appreciates the comments of the review committee. This project was supported by the National Science Council under Grant No.NSC101-2511-S-271 -001 and No. NSC102 - 2511 - S - 271 - 001.

\section{REFERENCES}

[1] Su, Y.C., "From the concept of knowledge-based economy on the educational administrative reforms," The Educator Monthly, 2002, vol. 423, pp. 28-31.

[2] Ramirez,C., Schau, C., \& Emmioğlu, E., "The Importance of Attitudes in Statistics Education," Statistics Education Research Journal, 2012, vol. 11(2), pp. 57-71.

[3] Schau, C. Emmioğlu, E., "Do Introductory Statistics Courses in the United States Improve Students' Attitudes?" Statistics Education Research Journal, 2012, vol. 11, no. 2, pp. 86 - 94.

[4] ChicK, H. L., \& Pierce, R. U., "Teachinf statistics at theprimary school level: Beliefs, affordances, and pedagogical content knowledge." In C. Batanero, G. Burrill, C. Reading, \& A. Rossman, 2008.

[5] Bruce, R.., "Creativity and instructional technology: great potential, imperfectly studied," Contemporary Educational Psychology, 1989, vol. 14, pp. 241-256.

[6] Fang, R. J., Chang, C. L., Tsai, H. L., \& Lee, C. J. “ Explain the Factors of Primary School Teachers Choosing Digitalized Teaching Materials with Theory of Planned Behavior," Proceedings of the $10^{\text {th }}$ WSEAS Int. Conference on MULTIMEDIA SYSTEM \& SIGNAL PROCESSING, 2010, pp. 77-83.

[7] Giller S, Barker P., "An evolving methodology for managing multimedia courseware production," Innovations in Education and Teaching International, 2006, vol. 43, no. 3, pp. 303-312.

[8] Chen, Su-Chang, Hsu, Chia-Wen, Lin, Hui-Chen \& Chou, Hung-Yi, "The Evaluation and using Intention for Digital Teaching Materials of Penghu Basalt," International Journal of Management \& Information Systems, 2010, Fourth Quarter, vol. 14, no.5, pp. 141-146.

[9] Lin, Chien-Heng \& Lou,Yu-Chiung, "A Framework of Multimedia Integration Basedon Teacher's Perspectives," British Journal of Education, Society \& Behavioural Science, 2013, vol. 3, no. 3, pp.345-358.

[10] Giller S, Barker P., "An evolving methodology for managing multimedia courseware production," Innovations in Education and Teaching International, 2006, vol. 43, no. 3, pp. 303-312.

[11] Moallem M., "An interactive online course: A collaborative design model," Educational Technology Research and Development, 2003, vol. 51, no. 4, pp. 85-103.

[12] Roblyer MD, Edwards J, Havriluk MA., Integrating educational technology into teaching. 4th ed. Upper Saddle River: NJ Prentice Hall, 2004.

[13] Wilson, B, Lowry, M., "Constructivist learning on the web," New Directions for Adults and Continuing Education, 2000, vol. 88, pp. 79-88.

[14] Aoyama, K., "Investigating a Hierarchy of Students' Interpretations of Graphs," International Electronic Journal of Mathematics Education, 2007, vol.2, no. 3, pp. 298-318.

[15] Garfield, J., Hogg, B., Schau, C., \& Whittinghill, D., "First Courses in Statistical Science: The Status of Educational Reform Efforts," Journal of Statistics Education, 2002, vol. 10, no. 2. [Online: www.amstat.org/publications/jse/v10n2/garfield.html]

[16] Lee, Y. J., "A study on the effect of teaching innovation on learnibg effectiveness with learning satisfaction as a mediator." World Transactions on Engineering and Technology Education, 2011, vol. 9, no 2, pp. 92-101.

[17] Schau, C., Stevens, J., Dauphinee, T. L., \& Del Vecchio, A., "The development and validation of the Survey of Attitudes Toward Statistics," Educational and Psychological Measurement, 1995, vol. 55, pp. 868-875.

[18] Fornell, \& Larcker., "Evaluating structural equation models with unobservable variables and measurement error," Journal of Marketing Research, 1981, vol. 18, no. 1, pp. 39-50.

[19] Kano,N.,Seraku,Takahadhi,F.\&Tsuji,S., "Attractive quality and must-be quality," Hinshitsu:The Journal of the Japanese Society for Quality Control, 1984(April), pp. 39-48.

[20] Lin, C. H., Shen, M. L., \& Lee, S. J., "The development of an Investigation Scale to Determine Preschool Teachers' Computer Attitudes," Asian Journal of Arts and Sciences, 2010, vol. 1, no. 1, pp. 141-153.

[21] Chance, B., Ben-Zvi, D., Garfield, J., \& Medina, E., "The Role of Technology in Improving Student Learning of Statistics," Technology Innovations in Statistics Education Journal, 2007, vol. 1, no. 1, pp.1-24. 